\title{
The future of self-assessment in classroom practice: Reframing self- assessment as a core competency
}

\author{
Gavin T. L. Brown ${ }^{a}$, Lois R. Harris ${ }^{b}$ \\ ${ }^{a}$ University of Auckland, New Zealand \\ ${ }^{\mathrm{b}}$ Central Queensland University, Australia \\ Article received $23^{\text {rd }}$ October $2013 /$ revised $7^{\text {th }}$ November $2013 /$ accepted $26^{\text {th }}$ February 2014 / available online $25^{\text {th }}$ April 2014
}

\begin{abstract}
Formative assessment policies and self-regulation theories argue that student selfassessment of their own work and processes are useful for raising academic performance and self-regulatory skills. However, research into student self-evaluation raises serious doubts about the quality of self-assessment as an assessment process and identifies conditions which must be met if students' judgments are to be useful, valid, and reliable. This paper recommends that student self-assessment should no longer be treated as an assessment, but instead as an essential competence for self-regulation. As such, we describe a potential curriculum approach that could guide teachers to appropriate use of self-assessment tools.
\end{abstract}

Keywords: Student Self-assessment; Compulsory Schooling; Curriculum; Research Synthesis

\section{Introduction}

Student self-assessment is an evaluation of a student's own work products and processes in classroom settings. Formative assessment (a.k.a., Assessment for Learning) policies argue that student self-assessment is useful for raising academic performance (Black \& Wiliam, 2006). Research evidence suggests that selfassessment does contribute positively to learning outcomes, but its effects are highly variable, with many threats to its validity (Brown \& Harris, 2013). Nonetheless, student self-assessment is strongly advocated as an important classroom practice (e.g., Leahy, Lyon, Thompson, \& Wiliam, 2005). This paper responds to recent and seminal reviews and position papers on self-assessment (e.g., Andrade, 2010; Brown \& Harris, 2013; Boud \& Falchikov, 1989; Butler, 2011; Falchikov \& Boud, 1989; Dochy, Segers, \& Sluijsmans, 1999;

Corresponding author: Associate Professor Gavin T L Brown, School of Learning, Development, \& Professional Practice, Faculty of Education, The University of Auckland, Private Bag 92019, Auckland, 1142, New Zealand, gt.brown@auckland.ac.nz. 
Dunning, Heath, \& Suls, 2004; Ross, 2006), all of which have raised issues to consider in relation to what is needed for the future of self-assessment. We are increasingly persuaded that self-assessment is not a robust assessment practice and that its real place in schooling is as a teachable and learnable component of selfregulated learning. However, current manifestations of self-assessment advocacy do not provide wellinformed guidance to researchers or practitioners about self-assessment. Hence, our goal is to first establish the need for a self-assessment curriculum and second to sketch out what that curriculum could look like.

\section{Self-assessment as assessment}

Assessment practices, which contribute to decision-making, need to be demonstrably valid and reliable (Messick, 1989). The usefulness of self-assessment for decision-making seems to depend, in part, upon whether the student can accurately or realistically judge the qualities of their own work. However, the realism or veridicality (i.e., truthfulness) of self-assessment are difficult to ascertain, since this can only be determined through comparison to other people's (e.g., teachers, peers, or parents) judgements or ratings or to performance on externally devised tests or examinations. As Butler (2011) makes clear, there has been a stream of research around student self-assessment that has emphasised the need for realistic, veridical, or verifiably accurate self-assessment if it is to effectively contribute to achievement (e.g., Brown \& Harris, 2013; Boud \& Falchikov, 1989; Falchikov \& Boud, 1989; Dunning, Heath, \& Suls, 2004; Ross, 2006). In contrast, there is another stream of research that has claimed that realism or veridicality in self-assessment is moot, since the self-assessment process helps students develop greater awareness of the quality of their work and criteria by which their work can be evaluated (e.g., Andrade, 2010). Butler (2011) concludes that the research in student self-assessment indicates that inaccurate, but positively biased, self-assessment leads to improved outcomes; while, inaccurate, negatively biased, self-assessment has a negative impact on achievement. Hence, while there is empirical and theoretical evidence for contrasting positions around the realism of student self-assessments, we take the position that if self-assessment is to contribute to highlyconsequential decision-making (e.g., teacher decisions about grouping, curriculum planning, or retention/promotion and student decisions about pursuing or dropping further study in a topic area), then it is necessary for self-assessments to be demonstrably realistic or truthful. The research evidence is robust that the agreement between student self-assessment and other measures (e.g., test scores, teacher judgements, or peer ratings) is moderate at best (Brown \& Harris, 2013; Falchikov \& Boud, 1989). Correlations between (a) self-ratings and teacher ratings, (b) self-estimates of performance and actual test scores, and (c) student and teacher rubric-based judgments tend to range from $r \approx .20$ to .80 , with few studies reporting correlations greater than $r>.60$ (Brown \& Harris, 2013). Greater realism and sophistication of self-assessment is more evident among more experienced and more able students.

Furthermore, consideration of how teachers use student self-assessment in classroom contexts suggests that there are other important factors which threaten reliability and validity. There is robust evidence that when self-assessments are disclosed (e.g., traffic light self-assessments displayed to the teacher in front of the class), there are strong psychological pressures on students that lead to dissembling and dishonesty (Harris \& Brown, 2013; Cowie, 2009). Students may intentionally disguise the truth in order to protect their reputations. Other students will rely on construct-irrelevant and subjective criteria (e.g., "I made an effort" or "I'm good at this"), rather than intended criteria in judging the quality of their performance and this is associated with lower accuracy in self-evaluations (Brown \& Harris, 2013). There are many factors in the human condition that contribute to unrealistic self-assessments, including tendencies to (a) be unrealistically optimistic about one's own abilities, (b) believe that one is above average, (c) neglect crucial information, and (d) have deficits in required information (Dunning, Heath, \& Suls, 2004). While substantial advocacy of self-assessment has been promulgated, these studies suggest that assessment for learning policies as implemented may have overlooked important facets of how humans make judgements. Further, there may be some psychological and social danger to students in current self-assessment practices.

Hence, awarding grades or basing educational interventions or changes based on unrealistic or construct-irrelevant self-assessments is untenable. If self-assessment processes lead students to conclude wrongly that they are good or weak in some domain and they base personal decisions on such false interpretations, harm could be done, even in classroom settings (e.g., task avoidance, not enrolling in future 
subjects) (Ramdass \& Zimmerman, 2008). The quality of interpretations and decisions depends on realistic input (Messick, 1989) and because students are generally unrealistic in self-assessments, the use of such data in any formal way for assessment is probably unwarranted. Hence, in many ways student self-assessment fails the validity and reliability requirements of an assessment robust enough on which to (a) base changes to classroom practice, (b) calculate grades or scores, and (c) include in any reporting.

\section{Self-assessment as self-regulation}

The use of self-assessment within assessment for learning policies draws on self-regulation of learning theories which identify student capabilities to set targets and evaluate progress against criteria as a basis for meta-cognitively informed improvement of learning outcomes (Zimmerman, 2008). Self-regulation refers to self-directive and self-generated metacognitive, motivational, and behavioural processes through which individuals transform personal abilities into control of outcomes in a variety of contexts (Zimmerman, 2001). In taking action, an individual requires the ability to understand and choose a rationale for taking action (i.e., motivation), the capacity to set future-oriented objectives, plans, or projects (i.e., goals), the capability to select means or methods for obtaining his or her goals, even in the face of adversity or boredom (i.e., strategies), and the proficiency to monitor progress (i.e., self-assess), and adjust strategy implementation as appropriate (i.e., regulation) (Brown, et al., 2005). There is evidence that students can improve their self-regulation skills through self-assessment (i.e., set targets, evaluate progress relative to target criteria, and improve the quality of their learning outcomes) (Andrade, Du, \& Wang, 2008; Andrade, Du, \& Mycek, 2010; Brookhart, Andolina, Zuza, \& Furman, 2004). Furthermore, self-assessment is associated with improved motivation, engagement, and efficacy (Griffiths \& Davies, 1993; Klenowski, 1995; Munns \& Woodward, 2006; Schunk, 1996), reducing dependence on the teacher (Sadler, 1989). It is also seen as a potential way for teachers to reduce their own assessment workload, making students more responsible for tracking their progress and feedback provision (Sadler \& Good, 2006; Towler \& Broadfoot, 1992). Thus, consistent with self-regulation theory, self-assessment contributes to greater meta-cognitive skills associated with greater achievement.

In reviewing literature around student self-assessment practices, Brown and Harris (2013) found diverse enacted practices which they grouped into three major categories (i.e., self-estimation of performance, self-rating, and rubric based judgements). These three categories contain a wide variety of procedures; for example, (a) using a model answer as a reference (Hewitt, 2001), (b) integrating teacherevaluation with self-evaluation (Olina \& Sullivan, 2002), (c) self-correction (Harward, Allred, \& Sudweeks, 1994), (d) using a computerized prompt system (Daiute \& Kruidenier, 1985), (e) self-selected reinforcements or rewards, especially for achieving challenging goals (Barling, 1980; Miller, Duffy, \& Zane, 1993; Wall, 1982), (f) contributing to the design of a scoring rubric (Sadler \& Good, 2006), or (g) judging the accuracy of answers to standardized test items (Koivula, Hassmén, \& Hunt, 2001). In contrast, inspection of recent pedagogical texts (e.g., Absolum, 2006; Clarke, 2005; Harlen, 2007; Taylor \& Nolen, 2005; Weeden, Winter, \& Broadfoot, 2002; Wiggins \& McTighe, 1998) indicates that a relatively narrow range of selfassessment techniques are suggested (e.g., rubrics, rating scales, including traffic lights, reflections on portfolios or series of tasks).

Further, we find no evidence of coherent packaging or sequencing of these activities or a theoretical model underpinning authors' recommendations of these practices. There seems to be an almost ad hoc, grab bag approach to the use of self-assessment. The templates given as examples in the texts we consulted included mainly checklists, rating scales (sometimes using smiley-face categories), and lists of possible prompting questions which focused on diverse outcomes including completion, compliance, effort, and attitude (e.g., McMillan, 2001; Stiggins, 2005), rather than necessarily upon the full-range of self-regulating behaviours. Also, textbooks seemed to treat the topic generically, without specifying ages or stages of development which would be appropriate for the practices, templates, or examples that they provided; it appears to be left to the reader to judge if a particular activity or prompt is appropriate for his or her students. Inspection of classroom practices of self-assessment reinforces this perception that teachers are applying self-assessment techniques with little thought as to potential threats to the validity of publicly displayed selfassessment (Harris \& Brown, 2013; Ross, Rolheiser, \& Hogaboam-Gray, 1998) and, certainly, have few 
concerns about the need to provide students structured support to enable them to use self-assessment realistically. This stands in stark contrast to the research literature that shows significant educational impact of self-assessment upon student learning, if students are systematically taught how to self-assess (Daiute \& Kruidenier, 1985; Glaser, Kessler, Palm, \& Brunstein, 2010; Harward, Allred, \& Sudweeks, 1994; McDonald \& Boud, 2003; Ramdass \& Zimmerman, 2008; Ross, 2006; Ross, Hogaboam-Gray, \& Rolheiser, 2002).

Hence, there is a clear need to give self-assessment techniques a semblance of order-identifying the ease or difficulty of implementation and use would provide a robust basis for developing a curriculum of self-assessment. Self-assessment is an essential component of self-regulation and would appear to be a learnable competence. The advantage of situating self-assessment as a competence is that competencies usually have levels of development (e.g., ranging from novice to expert) (Rychen \& Salganik, 2003) and, consequently, can be used as the basis for a teaching curriculum.

\section{Self-assessment as a curricular competence}

While the assessment for learning policy reforms have tried to move increasingly away from formal testing towards a more pedagogical understanding of 'assessment', and despite advocacy for the use of selfassessment as a component of self-regulation, little attention has been put into formalising a self-assessment curriculum, in light of well-established research findings. Insufficient attention has been given to curricular concerns, such as:

(a) What self-assessment skills should be taught?

(b) What is the developmental sequence for teaching self-assessment skills?

(c) How should self-assessment skills be taught?

(d) What are appropriate goals for teaching student self-assessment competence according to student age and ability?

(e) What are useful criteria for evaluating student competence in self-assessment?

(f) What are appropriate mechanisms by which student self-assessment reports could be evaluated, if required?

This paper offers a first attempt into developing a curriculum for self-assessment as a component of self-regulation. We appreciate that school curricula are overloaded and do not advocate for the creation of a new curricular topic. Instead, we suggest that within more general frameworks of teaching subject content and developing students as independent, life-long learners, the possession and implementation of a selfassessment curriculum is likely to be of great utility to teachers and students. As self-assessment is present in some forms already in most curricula, we are advocating for systematically organising and formalising what is, in most instances, already there. This would improve its impact and better match practices to student selfassessment abilities, allowing students opportunities to master more complex self-assessment and selfregulatory skills as they progress through school.

Lower performing and younger students need input (i.e., instruction and feedback) to master this key self-regulatory process. So what might that input look like? Research has shown (Brown \& Harris, 2013; Ross, 2006) that realistic self-assessments are more likely when: (1) students are involved in the process of establishing criteria for evaluating work outcomes; (2) students are taught how to apply those criteria; (3) students receive feedback from others (i.e., teachers and peers) to help move students toward more accurate evaluations; (4) students are taught how to use other assessment data (e.g., test scores or graded work) to improve their work; (5) there is psychological safety when self-evaluation is used; (6) when rewards for accuracy are used; and (7) when students are required to explicitly justify to their peers their self-evaluations. These insights give us a basis for developing a curriculum that could guide the implementation of student self-assessment as a necessary competence for self-regulation.

Our first recommendation for a student self-assessment curriculum is to start with simple, concrete techniques before introducing complex, abstract techniques, including holistic, intuitive judgements about 
effort, satisfaction, or work quality. For very young students, even the act of estimating how many times they would be able to throw a bean bag into basket was difficult (Powel \& Gray, 1995). Nonetheless, Powel and Gray's (1995) technique is extremely simple and the realism of a student self-assessment can be objectively verified by the student using a tangible metric. Hence, estimating how many items one might get right on a spelling list, math quiz, or vocabulary quiz are straightforward strategies which allow easy determination of the realism of the student self-assessment (Jones, Trap, \& Cooper, 1977; Wan-a-rom, 2010). Linking such estimates very close in time to the instructional moment also makes the task more concrete (Barnett \& Hixon, 1997). Even asking students to estimate how well they think they will do compared to their last known performance provides a concrete and personal reference point.

At an intermediate stage, self-assessments supported by externally-sourced, yet explicit scaffolding of intended learning outcomes (e.g., models, computer-assisted prompts, teacher evaluations) as an adjunct or guide should be introduced. More realistic comparisons of the student's work quality to that of other students in the class may be feasible here, but such normative comparisons may not be a desirable curricular goal. It seems more useful to have students focus on comparing their work to that of established standards or against their previous performance rather than on how others are doing. Nonetheless, techniques that allow greater autonomy in self-assessment (e.g., self-correction or self-rating of one's own work) should be introduced once students have demonstrated that they can assess their work realistically.

At an advanced stage, rubrics or criteria, preferably developed in conjunction with the students to ensure that they have a deep understanding of the rubric progression, should be introduced. By this point, students should be able to be reasonably realistic making use of more holistic, and possibly intuitive, judgements of their work quality using rating scales or key point checklists. The research shows that the greatest learning gains come when students engage in a deeper analysis of their own work; however, getting students to that level of analysis is unlikely to be instantaneous. Gradual introduction of more sophisticated self-assessment techniques seems highly desirable.

Throughout the development of self-assessment competence, the priority needs to be kept on realism in self-evaluation, regardless of the level of performance. We must help students avoid inappropriate negative bias in their self-assessments, which will mean helping highly able students accept that their work is actually exemplary or of a high standard. In contrast, while having an overly positive self-assessment does not have as many ill-effects (Butler, 2011), realism has its own internal benefits. Accurate self-monitoring contributes to the possibility of entering a growth-pathway in which students identify and respond to their weaknesses, instead of pursuing an ego-protection pathway in which students seek to maximise unmerited positive feelings about their work (Boekaerts \& Corno, 2005). Hence, teachers need to implement strategies that encourage and foster honest self-reflection. That will mean, at least for a time, permitting some selfassessments to remain private from the teacher, not forcing students to display realistic but negative selfassessments in front of classmates, and encouraging students to share their self-evaluations with trusted people (e.g., a best friend or a family member). This recommendation is not new; Andrade (2010) has long advocated focusing on the self-regulatory effects of self-assessment rather than its veridicality. And certainly, it means not using self-assessments for grading, reporting, or accountability purposes.

Nonetheless, students generally want to understand if they have judged their own work appropriately and expect teachers to provide feedback and instruction (Harris \& Brown, 2013; Gao, 2009; Peterson \& Irving, 2008). Thus, insulating student self-assessment perpetually from the teacher would be counterproductive. Hence, within a context of psychological safety, if teachers gain access to student selfassessments (e.g., those recorded alongside homework activities handed in to the teacher), it seems desirable for teachers to comment on the realism of student self-evaluations as an important learning objective in its own right. The goal is to foster realistic self-monitoring that is used to guide appropriate learning strategies (i.e., more sophisticated responses than 'work harder' are needed). Students need environments in which realism is prioritised and protected, even if it means, at first, teachers cannot easily ascertain what students think about their own learning. A self-assessment curriculum should also encourage students to explain the criteria they used to evaluate their own work. The intellectual sophistication required to justify an assessment is a significant factor in improving learning outcomes and metacognitive capability. In an environment of 
trust (e.g., a classroom with a warm supportive interpersonal climate), explaining one's reasoning for a selfassessment to a trusted peer is associated with improved learning outcomes (Dunning, Heath, \& Suls, 2004).

It should come as no surprise that both teachers and students will need training before they can engage with self-assessment as a taught and learned competence. New professional development materials and courses are needed that go beyond the exhortation to use student self-assessment (e.g., Leahy, Lyon, Thompson, \& Wiliam, 2005). These resources need to ensure teachers are aware of the theory and research base for self-assessment and provide techniques that are appropriately sequenced for the skill level students have in this competence. Until teachers abandon a simple approach (e.g., using smiley-face self-rating scales for effort and satisfaction), it is unlikely self-assessment will fulfil its promise. Once teachers have an appropriate understanding, they will need to train students in developing realistic self-evaluations for the explicit purpose of guiding their own learning. Fortunately, the research evidence makes it abundantly clear that the quality of student self-assessment improves with training and that enhanced outcomes arise.

While this paper provides a rough outline for the scope and sequence of a self-assessment curriculum, more research is needed to identify if there are ages or stages, below which, particular types of self-assessment are unrealistic for students to complete accurately. Additionally, a proper curriculum would incorporate all parts of the self-regulation cycle (Zimmerman, 2008) around the self-assessment practices proposed at particular levels. It is also important to invent new self-assessment practices which may better align with a complex model of self-regulation than current suggested self-reflection and self-assessment practices, most of which are focused at the end, rather than throughout, the learning cycle.

We trust that this treatment of self-assessment as a self-regulating competence, rather than an assessment practice, will contribute to improved classroom practice and professional development systems. We consider that a curriculum for self-assessment competence would be of great benefit to educational practice and trust that this first sketch will trigger significant developments.

\section{Keypoints}

- Student self-assessment generally has a positive impact on academic performance, although it is not a robust assessment method in terms of validity and reliability.

- Student self-assessment is an important aspect of and contributor to greater self-regulation of learning.

- Student self-assessment needs a curricular framework to ensure it is an effective treated as a self-regulating competence.

\section{Acknowledgments}

This paper was inspired by a presentation at the 2013 biennial meeting of the European Association for Research in Learning \& Instruction, Munich, Germany.

\section{References}

Absolum, M. (2006). Clarity in the classroom: Using formative assessment to build learning-focused relationships. Auckland, NZ: Hachette Livre New Zealand.

Andrade, H. L. (2010). Students as the definitive source of formative assessment: Academic self-assessment and the self-regulation of learning. In H. L. Andrade \& G. J. Cizek (Eds.), Handbook of formative assessment (pp. 90-105). New York: Routledge. 
Andrade, H. L., Du, Y., \& Mycek, K. (2010). Rubric-referenced self-assessment and middle school students' writing. Assessment in Education: Principles, Policy \& Practice, 17(2), 199-214. doi: 10.1080/09695941003696172

Andrade, H. L., Du, Y., \& Wang, X. (2008). Putting rubrics to the test: The effect of a model, criteria generation, and rubric-referenced self-assessment on elementary school students' writing. Educational Measurement: Issues and Practice, 27(2), 3-13. doi: 10.1111/j.1745-3992.2008.00118.x

Brown, G. T. L., \& Harris, L. R. (2013). Student self-assessment. In J. H. McMillan (Ed.). The SAGE handbook of research on classroom assessment (pp. 367-393). Thousand Oaks, CA: Sage.

Brown, G. T. L., Reddish, P., Leeson, H.V., Milfont, T.L., Brychkova, L. \& Hattie, J. A. C. (2005, June). Assessment of Key Competencies: A Proposal for Inclusion in e-asTTle. asTTle Advisory. Rep. 19, University of Auckland, Project asTTle.

Barling, J. (1980). A multistage multidependent variable assessment of children's self-regulation of academic performance. Child Behavior Therapy, 2(2), 43-54. doi: 10.1300/J473V02N02_03

Barnett, J. E., \& Hixon, J. E. (1997). Effects of Grade Level and Subject on Student Test Score Predictions. Journal of Educational Research, 90(3), 170-174. doi: 10.1080/00220671.1997.10543773

Black, P., \& Wiliam, D. (2006). Developing a theory of formative assessment. In J. Gardner (Ed.), Assessment and learning (pp. 81-100). London: Sage.

Boekaerts, M, \& Corno, L. (2005). Self-regulation in the classroom: A perspective on assessment and intervention. Applied Psychology: An International Review, 54(2), 199-231. doi: 10.1111/j.14640597.2005.00205.x

Boud, D., \& Falchikov, N. (1989). Quantitative studies of student self-assessment in higher education: a critical analysis of findings. Higher Education, 18, 529-549. doi: 10.1007/BF00138746

Brookhart, S. M., Andolina, M., Zuza, M., \& Furman, R. (2004). Minute Math: An Action Research Study of Student Self-Assessment. Educational Studies in Mathematics, 57(2), 213-227. doi: 10.1023/B:EDUC.0000049293.55249.d4

Butler, R. (2011). Are positive illusions about academic competence always adaptive, under all circumstances: New results and future directions. International Journal of Educational Research, 50(4), 251-256. doi: 10.1016/j.ijer.2011.08.006

Clarke, S. (2005). Formative assessment in the secondary classroom. Abingdon, UK: Hodder Murray.

Cowie, B. (2009). My teacher and my friends helped me learn: student perceptions and experiences of classroom assessment. In D. M. McInerney, G. T. L. Brown \& G. A. D. Liem (Eds.), Student perspectives on assessment: What students can tell us about assessment for learning (pp. 85-105). Charlotte, NC: Information Age Publishing.

Daiute, C., \& Kruidenier, J. (1985). A self-questioning strategy to increase young writers' revising processes. Applied Psycholinguistics, 6(3), 307-318. doi: 10.1017/S0142716400006226

Dochy, F., Segers, M., \& Sluijsmans, Dominique. (1999). The use of self-, peer- and co-assessment in higher education: A review. Studies in Higher Education, 24(3), 331-350. doi: 10.1080/03075079912331379935

Dunning, D., Heath, C., \& Suls, J. M. (2004). Flawed self-assessment: Implications for health, education, and the workplace. Psychological Science in the Public Interest, 5(3), 69-106. doi: 10.1111/j.15291006.2004.00018.x

Falchikov, N., \& Boud, D. (1989). Student self-assessment in higher education: A meta-analysis. Review of Educational Research, 59(4), 395-430. doi: 10.3102/00346543059004395

Gao, M. (2009). Students' voices in school-based assessment of Hong Kong: A case study. In D. M. McInerney, G. T. L. Brown \& G. A. D. Liem (Eds.), Student perspectives on assessment: What students can tell us about assessment for learning (pp. 107-130). Charlotte, NC: Information Age Publishing.

Glaser, C., Kessler, C., Palm, D., \& Brunstein, J. C. (2010). Förderung der Schreibkompetenz bei Viertklässlern: Spezifische und gemeinsame Effekte prozess- und egebnisbezogener Prozeduren der Selbstgregulation auf Indikatoren der Schreibleistung, Strategiebeherrschung und Selbstbewertung [Improving fourth graders' self-regulated writing skills: Specialized and shared effects of processoriented and outcome- related self-regulation procedures on students' task performance, strategy use, 
and self-evaluation]. Zeitschrift fur Padagogische Psychologie/ German Journal of Educational Psychology, 24(3-4), 177-190. doi: 10.1024/1010-0652/a000015

Griffiths, M., \& Davies, C. (1993). Learning to learn: Action research from an equal opportunities perspective in a junior school. British Educational Research Journal, 19(1), 43-58. doi: 10.1080/0141192930190104

Harlen, W. (2007). Assessment of learning. Los Angeles: Sage.

Harris, L. R., \& Brown, G. T. L. (2013). Opportunities and obstacles to consider when using peer- and selfassessment to improve student learning: Case studies into teachers' implementation. Teaching and Teacher Education, 36, 101-111. doi: 10.1016/j.tate.2013.07.008

Harward, S. V., Allred, R. A., \& Sudweeks, R. R. (1994). The effectiveness of our self-corrected spelling test methods. Reading Psychology, 15(4), 245-271. doi: 10.1080/0270271940150403

Hewitt, M. P. (2001). The effects of modeling, self-evaluation, and self-listening on junior high instrumentalists' music performance and practice attitude. Journal of Research in Music Education, 49(4), 307-322. doi: 10.2307/3345614

Jones, J, C., Trap, J., \& Cooper, J. O. (1977). Technical report: Students' self-recording of manuscript letter strokes. Journal of Applied Behavior Analysis, 10(3), 509-514. doi: 10.1901/jaba.1977.10-509

Klenowski, V. (1995). Student self-evaluation processes in student-centred teaching and learning contexts of Australia and England. Assessment in Education: Principles, Policy \& Practice, 2(2), 145-163. doi: 10.1080/0969594950020203

Koivula, N., Hassmén, P., \& Hunt, D. P. (2001). Performance on the Swedish Scholastic Aptitude Test: Effects of self-assessment and gender. Sex Roles: A Journal of Research, 44(11), 629-645. doi: 10.1023/A:1012203412708

Leahy, S., Lyon, C., Thompson, M., \& Wiliam, D. (2005). Classroom assessment minute by minute, day by day. Educational Leadership, 63(3), 18-24.

McDonald, B., \& Boud, D. (2003). The impact of self-assessment on achievement: The effects of selfassessment training on performance in external examinations. Assessment in Education: Principles, Policy \& Practice, 10(2), 209-220. doi: 10.1080/0969594032000121289

McMillan, J. H. (2001). Classroom assessment: Principles and practice for effective instruction (2nd ed.). Boston, MA: Allyn \& Bacon.

Messick, S. (1989). Validity. In R. L. Linn (Ed.), Educational Measurement (3rd ed., pp. 13-103). Old Tappan, NJ: MacMillan.

Miller, T. L., Duffy, S. E., \& Zane, T. (1993). Improving the accuracy of self-corrected mathematics homework. Journal of Educational Research, 86(3), 184-189. doi: 10.1080/00220671.1993.9941157

Munns, G., \& Woodward, H. (2006). Student Engagement and Student Self-Assessment: The REAL Framework. Assessment in Education: Principles, Policy and Practice, 13(2), 193-213. doi: 10.1080/09695940600703969

Olina, Z., \& Sullivan, H. J. (2002). Effects of classroom evaluation strategies on student achievement and attitudes. Educational Technology, Research and Development, 50(3), 61-75. doi: 10.1007/BF02505025

Peterson, E. R., \& Irving, S. E. (2008). Secondary school students' conceptions of assessment and feedback. Learning and Instruction, 18(3), 238-250. doi: 10.1016/j.learninstruc.2007.05.001

Powel, W. D., \& Gray, R. (1995). Improving performance predictions by collaboration with peers and rewarding accuracy. Child Study Journal, 25(2), 141-154.

Ramdass, D., \& Zimmerman, B. J. (2008). Effects of self-correction strategy training on middle school students' self-efficacy, self-evaluation, and mathematics division learning. Journal of Advanced Academics, 20(1), 18-41. doi: 10.4219/jaa-2008-869

Ross, J. A. (2006). The reliability, validity, and utility of self-assessment. Practical Assessment Research \& Evaluation, 11(10), Available online: http://pareonline.net/getvn.asp?v=11\&n=10.

Ross, J. A., Hogaboam-Gray, A., \& Rolheiser, C. (2002). Student self-evaluation in Grade 5-6 mathematics: Effects on problem-solving achievement. Educational Assessment, 8(1), 43-59. doi: 10.1207/S15326977EA0801_03 
Ross, J. A., Rolheiser, C., \& Hogaboam-Gray, A. (1998). Skills training versus action research in-service: impact on student attitudes to self-evaluation. Teaching and Teacher Education, 14(5), 463-477. doi: 10.1016/S0742-051X(97)00054-1

Rychen, D. S., \& Salganik, L. H. (2003). A holistic model of competence. In D. S. Rychen \& L. H. Salganik (Eds.). Key Competencies for a Successful Life and a Well-Functioning Society (pp. 41-62). Cambridge, MA: Hogrefe \& Huber.

Sadler, P. M., \& Good, E. (2006). The impact of self- and peer-grading on student learning. Educational Assessment, 11(1), 1-31. doi: 10.1207/s15326977ea1101_1

Sadler, R. (1989). Formative assessment and the design of instructional systems. Instructional Science, 18, 119-144. doi: 10.1007/BF00117714

Schunk, D. H. (1996). Goal and self-evaluative influences during children's cognitive skill learning. American Educational Research Journal, 33(2), 359-382. doi: 10.2307/1163289

Stiggins, R. J. (2005). Student-involved assessment FOR learning (4th ed.). Upper Saddle River, NJ: Pearson Education.

Taylor, C. S., \& Nolen, S. B. (2005). Classroom assessment: Supporting teaching and learning in real classrooms. Upper Saddle River, NJ: Pearson Education.

Towler, L., \& Broadfoot, P. (1992). Self-assessment in the primary school. Educational Review, 44(2), 137151. doi: 10.1080/0013191920440203

Wall, S. M. (1982). Effects of systematic self-monitoring and self-reinforcement in children's management of test performances. Journal of Psychology, 111(1), 129-136. doi: 10.1080/00223980.1982.9923524

Wan-a-rom, U. (2010). Self-assessment of word knowledge with graded readers: A preliminary study. Reading in a Foreign Language, 22(2), 323-338.

Weeden, P., Winter, J., \& Broadfoot, P. (2002). Assessment: What's in it for schools? London: RoutledgeFalmer.

Wiggins, G. P., \& McTighe, J. (1998). Understanding by design. Alexandria, VA: Association for Supervision and Curriculum Development.

Zimmerman, B. J. (2001). Theories of self-regulated learning and academic achievement: An overview and analysis. In B. J. Zimmerman \& D. H. Schunk (Eds.). Self-Regulated Learning and Academic Achievement: Theoretical Perspectives ( $2^{\text {nd }}$ edn.). Mahwah, NJ: LEA.

Zimmerman, B. J. (2008). Investigating self-regulation and motivation: Historical background, methodological developments, and future prospects. American Educational Research Journal, 45(1), 166-183. doi: 10.3102/0002831207312909 